\title{
Improvement of Dietary Total Calcium to Inorganic Phosphorus Ratio Prevents Progressive Nutritional Secondary Hyperparathyroidism in Ponies and Donkeys
}

\author{
Naoki SASAKI ${ }^{1}{ }^{* *}$, Tomomi SHIMODA ${ }^{1}$, Motoyoshi SATO ${ }^{1}$, Hidefumi FURUOKA ${ }^{2}$, \\ Wataru MIKI ${ }^{3}$, Inhyung $\mathrm{LEE}^{4}$ and Haruo YAMADA ${ }^{1}$ \\ ${ }^{1}$ Departments of Clinical Veterinary Science and ${ }^{2}$ Pathological Science, Obihiro University of Agriculture \& \\ Veterinary Medicine, Inada, Obihiro, Hokkaido 080-8555, ${ }^{3}$ Tokachi NOSAI Central Domestic Animal Clinical \\ Center, Motoimatsu, Obihiro, Hokkaido 080-2331, Japan, ${ }^{4}$ Department of Neuroscience and Cell Biology, \\ University of Texas Medical Branch, 301 University Boulevard, Galveston, TX 77555-1069, U.S.A.
}

Five ponies and two donkeys suspected of having nutritional secondary hyperparathyroidism (NSH) were put on an improved diet with a phosphorus:calcium ratio of 1:1.5. Changes in serum phosphorus, calcium, intact-PTH, and calcitonin concentrations were monitored for 1 year. High levels of phosphorus, intact-PTH, and calcitonin in the blood caused by NSH were significantly reduced two months after the improved diet was started, although the calcium level in the blood hardly changed $(P<0.05)$. Therefore a diet with well balanced minerals can help ponies and donkeys recover from NSH.

Key words: nutritional secondary hyperparathyoidism, parathyroid hormone, phosphorus and calcium balance, pony
J. Equine Sci.

Vol. 16, No. 3

pp. 79-83, 2005
Nutritional secondary hyperparathyroidism (NSH) occurs in horses fed a diet low in calcium, high in phosphorus or both for a long time [3]. The feeding of a high phosphorus diet results in high phosphorus concentration in the blood, which stimulates the parathyroid gland to overproduce the parathyroid hormone (PTH) leading to increased bone resorption. The clinical signs of NSH are miscarriage, lameness, fracture, facial swelling and increased bone penetration by X-rays [3]. Horses with NSH show high serum concentrations of phosphorus and intact-PTH. Horses with NSH show lack of bone density, and their trabeculae, located within the resorption (Howship's lacunae) bone, are replaced with fibrocellular masses [2].

A Shetland pony mare (pony 1) kept on a farm in Tokachi, Hokkaido had been fed a diet low in calcium and high in phosphorus (P:Ca=5:1) since fall 2002. The pony was referred to Obihiro University in spring

This article was accepted May 18, 2005

*Corresponding author. e-mail: naoki@obihiro.ac.jp
2003 because of astasia and fractures of the forelegs and hind legs and showed clinical signs (miscarriage, bone fractures) and pathological signs (swollen parathyroid, bone replaced by fibrous tissue and formation of Howship's lacunae) of NSH $[1-5,14]$. The owner of the pony had at the same stable five ponies [two stallions (pony 2,3) and three mares (pony 4-6)] and two donkeys [a stallion (donkey 1) and a mare (donkey 2)] that had also been fed a high phosphorus/low calcium diet for more than half a year and consequently were showing clinical signs (miscarriage, lameness) of NSH.

Although many studies have reported the causes and clinical signs of NSH [2, 3, 11, 12, 14], only few reports have investigated the effects of an improved diet on NSH.

The objectives of this study were to correct the balance of phosphorus and calcium intake of the ponies (pony 2-6) and donkeys (donkey 1, 2), and to determine the physiological changes occurring during NSH.

Pony 1 was submitted for postmortem necropsy and 
Table 1. Age, sex and body weight of the ponies and donkeys used in this study

\begin{tabular}{lrll}
\hline & Age & Sex & Weight $(\mathrm{kg})$ \\
\hline pony No. 1 & 10 & mare & not weighted \\
pony No. 2 & 7 & stallion & 254 \\
pony No. 3 & 2 & stallion & not weighted \\
pony No. 4 & 7 & mare & 168.5 \\
pony No. 5 & 5 & mare & 175.5 \\
pony No. 6 & 4 & mare & 203 \\
donky No. 1 & 4 & stallion & 137 \\
donky No. 2 & 6 & mare & 185.5 \\
\hline mean \pm S.D. & & & $187.3 \pm 39.3$ \\
\hline
\end{tabular}

ponies 2-6 and donkeys 1, 2 were put on an improved diet from April 2003 to April 2004. Ponies 2-6 and donkeys $1,2[5.0 \pm 1.4$ years, $187.3 \pm 39.3 \mathrm{~kg}$ (mean \pm S.D.) ] had been fed during the previous 6 months, $2 \mathrm{~kg}$ per day of bran and corn silage ad libitum. The phosphorus calcium ratio of this feed was about 5:1 (Japan Feeding Standard for Horses, 1998). However, the optimum dietary phosphorus calcium ratio is $1: 1.5$ $[9,10]$. To achieve this ratio, the animals were fed $1 \mathrm{~kg}$ per day of bran and orchard hay or timothy and clover grass ad libitum, supplemented with $50 \mathrm{~g}$ of calcium (Mash Rincal 3, Mercian, Tokyo). Serum phosphorus, calcium, intact-PTH, and calcitonin concentrations were measured in each animal monthly from April 2003 to October 2003 and in April 2004.

Blood samples were collected in plain tubes from the jugular vein using a 21-gauge needle. After each collection, blood samples were centrifuged $(1,600 \times \mathrm{g}$, $15 \mathrm{~min}$ ) and the resulting serum samples were stored at $-20^{\circ} \mathrm{C}$ until analysis.

Serum phosphorus concentrations $(\mathrm{mg} / \mathrm{d} l)$ were measured by an enzyme method and serum calcium concentrations $(\mathrm{mg} / \mathrm{d} l)$ were measured by the o-cresol phthalein method, both methods using an autoanalyzer (TBA-30R, Toshiba, Tokyo). Serum intactPTH concentrations $(\mathrm{pg} / \mathrm{m} l)$ were measured by a chemiluminescence immunoassay (Allegro Light intact-PTH kit, Kyowa Medex, Tokyo), and serum calcitonin concentrations $(\mathrm{pg} / \mathrm{m} l)$ were measured by radioimmunoassay (calcitonin RIA YUKA kit, Mitsubishi Chemistry, Ibaraki).

During each examination, the animal was palpated and its temperature, breathing rate, heart beat, blood count, and blood biochemistry were determined.

Values are expressed as the mean \pm S.D. Statistical differences between concentrations for each month were analyzed by the Kruskal-Wallis test, and months were compared using the multiple comparison test (Scheffe's F). Differences were considered significant when $\mathrm{P}<0.05$.

Pony 1 had severe syntexis and astasia, a right radius open fracture, left second phalanx double fracture, right hind first phalanx joint open luxation, and left third metacarpal bone double fracture. The parathyroid showed marked bilateral swelling (Fig. 1) and its microscopic examination revealed inflated chief cells with clear cytoplasm (Fig. 2). The ribs and shank bones showed newly formed dense fibrous tissue (Fig. 3) and extensive resorption with numerous Howship's lacunaes (Fig. 4). Based on these clinical signs and pathological findings, pony 1 was diagnosed with NSH.

In ponies 2-6 and donkeys 1,2 , the mean serum phosphorus concentration before starting the improved diet (April 2003) much higher than of normal horses $(7.3 \pm 1.8 \mathrm{mg} / \mathrm{d} l$ vs. $1.1-4.4 \mathrm{mg} / \mathrm{d} l$, Fig 5). However, after starting the improved diet (June 2003 to October 2003 and April 2004) the mean serum phosphorus concentration was significantly lower than that measured in April 2003 (Fig. 5, $\mathrm{P}<0.05$ ).

The mean serum calcium concentration was normal in all ponies (2-6) and donkeys (1, 2) (10.7-12.4 mg/ $\mathrm{m} l$ [13]) throughout the experimental period. However, in May 2003 (one month after starting the improved diet) the mean serum calcium concentration was slightly lower than normal (Fig. 6).

The mean serum intact-PTH concentration before starting the improved diet (April 2003) was significantly higher than that measured in June, July, August, and September 2003, and in April 2004 (45.6 $\pm 31.3 \mathrm{pg} / \mathrm{m} l$ vs. $17.8 \pm 1.7 \mathrm{pg} / \mathrm{ml}$ (June), $26.7 \pm 8.2 \mathrm{pg} / \mathrm{m} l$ (July), $32.0 \pm 10.0 \mathrm{pg} / \mathrm{m} l$ (August), $25.8 \pm 10.6 \mathrm{pg} / \mathrm{m} l$ (September), $42.6 \pm 15.4 \mathrm{pg} / \mathrm{ml}$ (April 2004), respectively, Fig. 7). Although in May 2003 and October 2003 the mean serum intact-PTH concentration was lower than that measured before starting the improved diet (April 2003) the difference was not statistically significant.

The mean serum calcitonin concentration before starting the improved diet was higher than that in normal horses $(47.3 \pm 25.9 \mathrm{pg} / \mathrm{m} l$ vs. $0-20 \mathrm{pg} / \mathrm{ml}$ [10], Fig. 8). In June 2003, the mean serum calcitonin concentration $(17.8 \pm 1.7 \mathrm{pg} / \mathrm{ml}$ ) was significantly lower than that in April 2003 (Fig. 8, $\mathrm{P}<0.05$ ).

Before starting the improved diet, donkey 1 had severe right hind leg lameness. Donkey 2 and pony 4 had experienced repeated abortions. However, after being put on the improved diet, all ponies and donkeys 


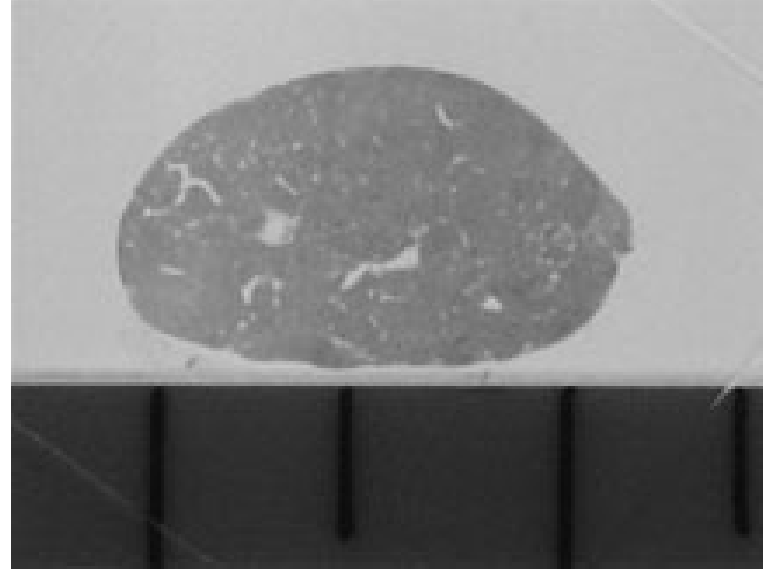

Fig. 1. Section of the parathyroid of pony 1 showing marked bilateral swelling (scale: $5 \mathrm{~mm}$ ).

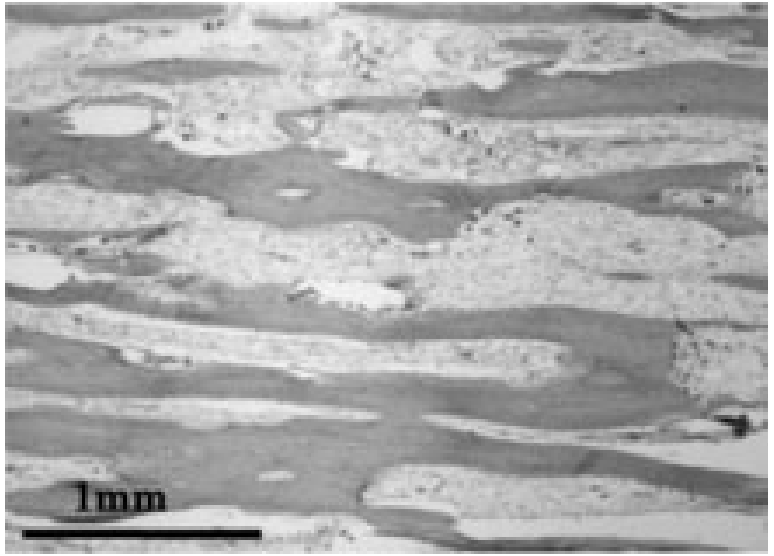

Fig. 3. Section of a rib of pony 1 showing newly formed dense fibrous tissue (H-E staining).

showed no clinical signs of NSH. In addition, pony 3 that was pregnant before the improved diet was begun, delivered a healthy foal in November. Pony 4 and donkey 2 became pregnant after the improved diet was started and had no miscarriage during the experimental period. The lameness experienced by donkey 1 disappeared after one month of the improved diet with no relapse noted thereafter.

As all ponies and donkeys examined in this study had been fed a high phosphorus/low calcium diet, their serum phosphorus and intact-PTH concentrations were high. Thus, it is likely that the animals had a low calcium/high phosphorus absorption in the bowel.

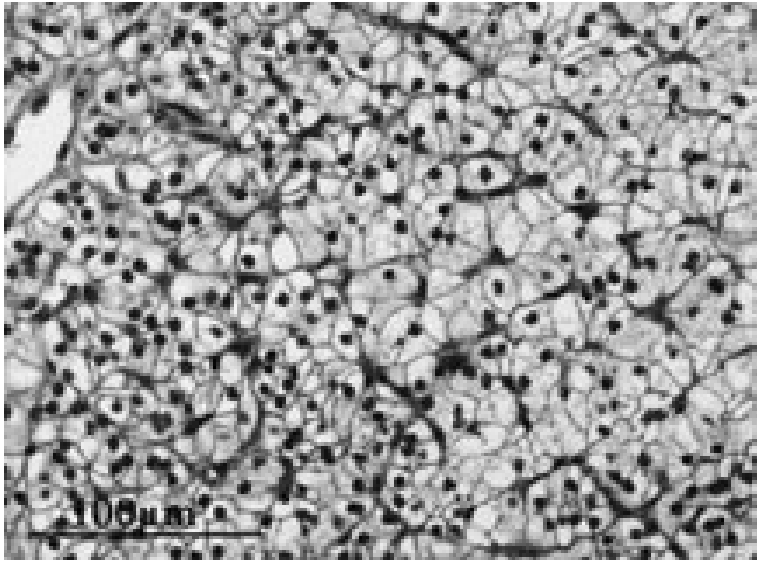

Fig. 2. Section of the parathyroid of pony 1 viewed under the microscope Chief cells are inflated and have clear cytoplasm (H-E staining).

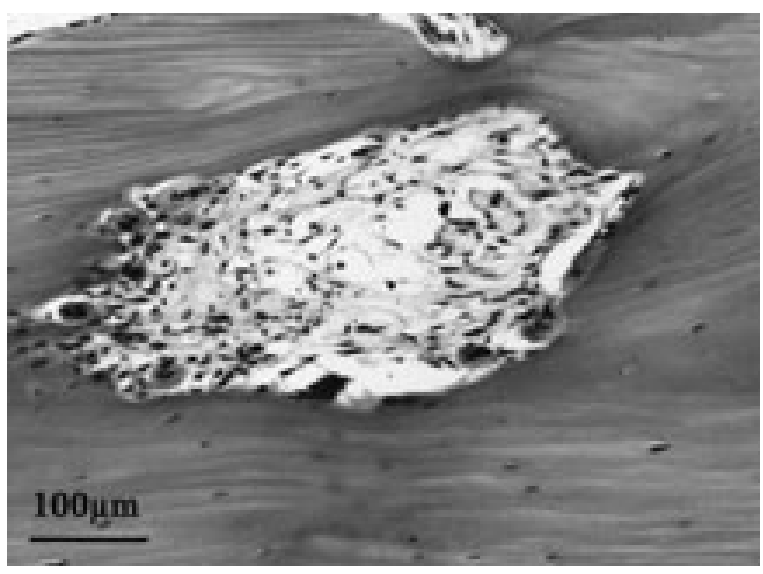

Fig. 4. Section of the shank bone of pony 1 viewed under the microscope Howship's lacunaes are shown (H-E staining).

High serum phosphorus concentration stimulates the parathyroid gland leading to an over production of PTH, which causes extrication of phosphorus and calcium by bone. Reversibly, the serum phosphorus concentration was high because of high phosphorus absorption in the bowel and extrication of phosphorus by bone, which again stimulates the parathyroid gland leading to an over production of PTH. Thus the ponies and donkeys were in a vicious cycle as their parathyroids were swelling gradually, extending the occurrence of clinical signs of NSH.

Horses experience a calcium deficiency if they consume a diet with phosphorus:calcium ratio of less 


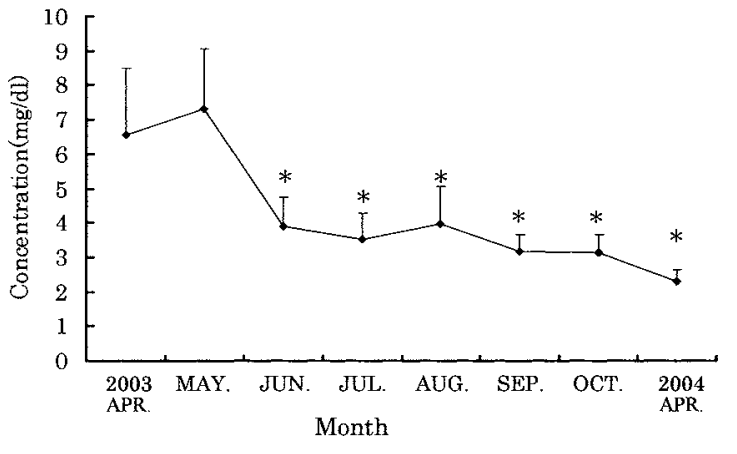

Fig. 5. Changes in serum phosphorus concentration during the experimental period (April 2003-April 2004). Values are expressed as the mean \pm S.D. $(\mathrm{n}=7)$.

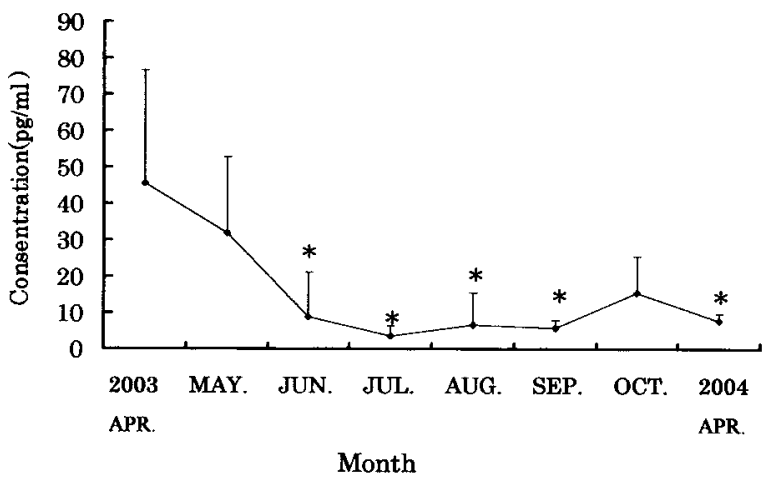

Fig. 7. Changes in serum intact-PTH concentration during the experimental period (April 2003-April 2004). Values are expressed as the mean \pm S.D. $(n=7)$.

than 1:1 [9]. The recommended phosphorus:calcium ratio is $1: 1.5[9,10]$. Therefore, to improve the condition of the animals used in this study a calcium supplement ( $50 \mathrm{~g}$ calcium) was daily added to their diet to bring the phosphorus:calcium ratio to about 1:1.5. This improved diet was recommended by L.D. Lewis in Equine Clinical Nutrition, 1995.

In normal horses, serum phosphorus concentration ranges between $1.1-4.4 \mathrm{mg} / \mathrm{d} l$ [13]. Serum phosphorus concentrations in the animals used in this study were higher than normal in April 2003 before the improved diet was started, and the same was true one month later (May 2003). It has been reported that serum intact-PTH concentration in normal horses varies between $20-30 \mathrm{pg} / \mathrm{m} l$ [7]. Serum intact-PTH concentration in the experimental animals of this study was higher than normal in April 2003 before the

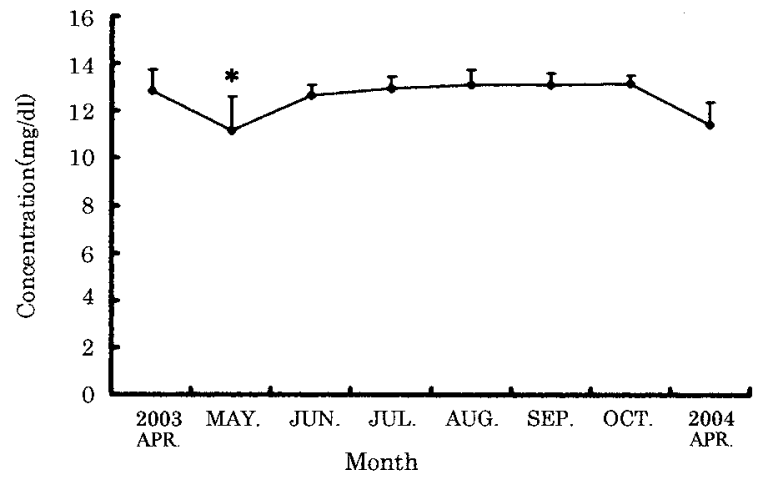

Fig. 6. Changes in serum calcium concentration during the experimental period (April 2003-April 2004). Values are expressed as the mean \pm S.D. $(n=7)$.

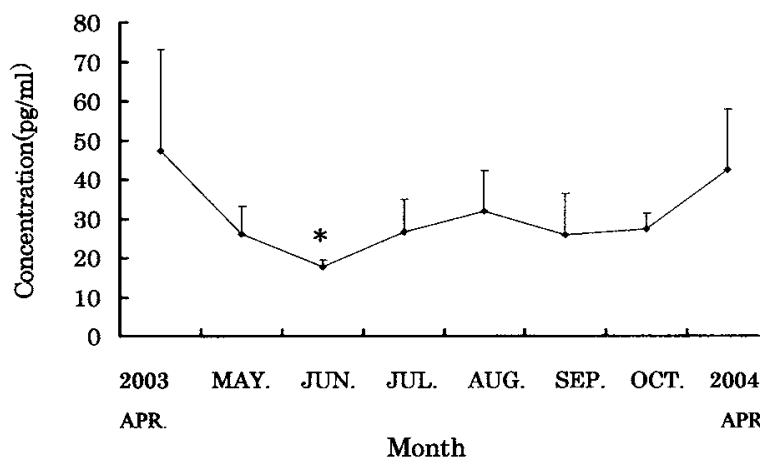

Fig. 8. Changes in serum calcitonin concentration during the experimental period (April 2003-April 2004). Values are expressed as the mean \pm S.D. $(n=6)$.

improved diet was started indicating that these animals had NSH. After the animals were put on a diet with improved mineral balance, serum phosphorus and intact-PTH concentrations decreased significantly. Feeding animals a diet with a phosphorus:calcium ratio of 1:1.5 can normalize serum phosphorus and intactPTH concentrations in about two months.

The serum calcium concentration of normal horses ranges between $10.7-12.4 \mathrm{mg} / \mathrm{d} l$ [13], and hardly changes in horses with NSH [10]. Indeed, in this study serum calcium concentration in the experimental animals was in the normal range throughout the experimental period. Calcium affects many neural and muscle functions, and its concentration in the blood is strictly controlled [6]. On the other hand, after one month of the improved diet, the serum calcium concentration was lower than that measured in April 
2003 before the improved diet was begun, and it was significantly lower from June to October 2003. This decrease in serum calcium concentration can be regarded as being due to a dramatic change in the animals' internal functions.

In normal horses, the serum calcitonin concentration has been reported to vary between $0-20$ $\mathrm{pg} / \mathrm{m} l[8]$. In this study, the serum calcitonin concentration after the animals were put on an improved diet was significantly lower than that measured in April 2003, before the improved diet was started. In May, July, August, September and October 2003, it stayed higher than the normal values throughout the experimental period. Serum calcitonin concentration, which normally decreases with serum calcium concentration, was increased with calcium deficiency. This increase can be regarded as evidence of serum calcium concentration controlled by excessive PTH secretion resulting in phosphorus and calcium release by bones.

After being put on the improved diet, donkey 1 recovered from its lameness, and the ponies and donkey 2 had no miscarriages. It is probable that the animals' NSH had abated as a result of the new diet and that calcium absorption in the bowel was no longer inhibited. The new improved diet decreased serum phosphorus concentration and consequently PTH secretion. These changes resulted in normal bone release and absorption of calcium and phosphorus.

In conclusion, this study shows that recovery from NSH requires changes in serum phosphorus, calcium, intact-PTH and calcitonin concentrations and that high serum phosphorus and intact-PTH concentrations caused by NSH in horses can be normalized by a well balanced diet. Therefore, improving the mineral balance of diet can help horses recover from NSH.

\section{References}

1. Argenzio, R.A., Lowe, J.E., Hintz, H.F., and Schryver, H.F. 1973. Calcium and phosphorus homeostasis in Horses. J. Nutr. Jpn. 104: 18-27.

2. Benders, N.A., Junker, K., Wensing, T., Van, T.S. and Van, J.H. 2001. Diagnosis of secondary hyperparathyroidism in a pony using intact parathyroid hormone radioimmunoassay. Vet. Rec. 149: 185-187.
3. Brook, D. 1975. Osteoporosis in a six year old pony. Equine Vet. J. 7: 46-48.

4. Calvo, M.S. 1994. The effects of high phosphorus intake on calcium homeostasis. Adv. Nutr. Res. 9: 183-207.

5. Chiba, S., Kanematsu, S., Murakami, K., Sato, A., Asahina, M., Numakunai, S., Goryo, M., Ohshima, K., and Okada, K. 2000. Serum parathyroid hormone and calcitonin levels in Racehorses with fracture. J. Vet. Med. Sci. 62: 361-365.

6. Estepa, J.C., Aguilera, T.E., Mayer, V.R., Almaden, Y., Felsenferd A.J., and Rodriguez, M. 1998. Measurement of parathyroid hormone in horses. Equine Vet. J. 30: 476-481.

7. Frape, D.L. 1999. The roles of major minerals and trace elements. pp.43-47. In: Equine Nutrition and Feeding (Frape D.L. eds.), Blackwell Science, Oxford.

8. Garel, J.M., Martin, R.W., and Barlet, J.P. 1975. Plasma immunoreactive calcitonin levels in pregnant mares and newbone foals. Horm. Metab. Res. 7: 429-432.

9. Lewis, L.D. 1995. Minerals for horses. pp.25-35. In: Equine Clinical Nutrition Feeding and Care (Lewis, L.D. ed.), Williams \& Wilkins, Philadelphia.

10. Lewis, L.D. 1995. Equine nutritional requirements, feed composition, and conversion tables. pp.548-564. In: Equine Clinical Nutrition Feeding and Care(Lewis, L.D. ed.), Williams \& Wilkins, Philadelphia.

11. McKenzie, R.A., Gartner, R.J.W., Blaney, B.J., and Glanville, R.J. 1981. Control of Nutritional Secondary hyperparathyroidism in grazing horses with calcium plus phosphorus supplementation. Aus. Vet. J. 57: 554-557.

12. Miyamoto, K., Ito, M., Segawa, H., and Kuwahata, M. 2000. Secondary hyperparathyroidism and phosphate sensing in parathyroid glands. J. Med. Invest. 47: 118-122.

13. Robinson, N.E. 2003. Normal clinical pathology data. pp.876. In: Current therapy in equine medicine. (Robinson N.E. eds.), Saunders, Missouri.

14. Rosen, N., Van H.J., and Van, A.S.R., 1992. Clinical and biochemistry findings, and parathyroid hormone concentrations in three horses with secondary hyperparathyroidism. S. Afr. Vet. Ver. 63: 134-136. 